\title{
Flocculation Efficiency of Sludge Bioflocculant for Treating Two Kinds of Simulated Wastewater
}

\author{
Xiu-Hong ZHANG ${ }^{1, a}$, Lian ZHANG ${ }^{1}$, Jun-Kang ZOU ${ }^{1}$ and Jing WANG ${ }^{2, ~ *}$ \\ ${ }^{1}$ School of chemistry, Dalian University of Technology, Dalian 116024, Liaoning, China \\ ${ }^{2}$ School of Environmental Science and Technology, Dalian University of Technology, Dalian 116024, \\ Liaoning, China \\ atgazxh@163.com \\ ${ }^{*}$ Corresponding author
}

Keywords: Excess Biological Sludge, Recycling; Bioflocculant, Wastewater Treatment.

\begin{abstract}
Sludge bioflocculant was prepared from excess biological sludge by extraction method with dilute hydrochloric acid. A series of experiments were performed to investigate the flocculation efficiency of sludge bioflocculant towards starch and oily wastewater. The results indicated that the sludge bioflocculant had good efficiency towards starch and oily wastewater. More than $90 \%$ of flocculating rates were attained for the two kinds of wastewater. From the above study not only sludge could be recycled, a cheaper and readily available flocculant was attained from biological sludge, but also some kinds of wastewater could be treated with the sludge flocculant.
\end{abstract}

\section{Introduction}

Excess biological sludge is an aggregate of microorganisms organism and inorganism which are discharged from wastewater processing system $[1,2]$. Thus excess biological sludge is supposed to be a source of bioflocculants and could be recycled to prepare bioflocculant. In the previous work, we successfully extracted flocculation active ingredient from sludge and $98 \%$ of flocculation efficiency for kaolin suspension was attained [3].

Nowadays various kinds of sewage are generated with the rapid development of industry and agriculture which brings risk for human health and environment [4]. Directly emitted starch wastewater can consume the dissolved oxygen in the water, leads to the deterioration of the environment. Therefore, to improve the quality of starch wastewater treatment and comprehensive recycling, environmental scientists pay more attention to it $[5,6]$. Oily wastewater is also one of the priority control pollutants. Therefore, an effective and economical flocculant, which is capable of dealing with the ever increasing demand, is desirable for industrial application.

In this paper, hydrochloric acid was applied to disintegrate excess biological sludge to extract flocculating activity ingredients which was defined as sludge bioflocculant (SBF). The flocculation conditions for wastewater treatment with SBF were researched. From the above study not only a cheaper and readily available flocculant was attained, but also some kinds of wastewater could be disposed of with the sludge flocculant.

\section{Materials And Methods}

\section{Preparation of SBF}

Before extracting sludge bioflocculants, $100.0 \mathrm{~mL}$ sodium hydroxide solution $(4 \%$, w/w) was used to soak $30.0 \mathrm{~g}$ dewatered sludge. During the soaking time, the mixed system was stirred by a magnetism mixer at 400 rpm for 40min and then centrifuged at $8000 \mathrm{rpm}$ for $15 \mathrm{~min}$. The sediment was washed to neutral with deionized water and centrifuged at the same speed. The rest sediment was defined as one piece of neutral sludge.

Hydrochloric acid $(3 \%, \mathrm{w} / \mathrm{w}) 60.0 \mathrm{~mL}$ was mixed with one piece of neutral sludge, and then the 
sludge suspension was stirred with magnetic stirrers at $400 \mathrm{rpm}$ for $15 \mathrm{~min}$. The suspension was centrifuged at $8000 \mathrm{rpm}$ for $15 \mathrm{~min}$. The supernatant liquor was diluted to $150.0 \mathrm{~mL}$ with deionized water. This supernatant liquor was defined as crude bioflocculant. The crude bioflocculant was fractional precipitated by increasing supernatant liquor $\mathrm{pH}$ to 9.0 with sodium hydroxide solution $(4 \%, \mathrm{w} / \mathrm{w})$ and the sediment was got by centrifugation at $8000 \mathrm{rpm}$ for $15 \mathrm{~min}$. The above sediment was feed into dialysis bags which molecular weight cut off was 10,000Da. After dialysis, this kind of purified sludge bioflocculants were evaporated $2 \mathrm{~h}$ for dryness then the dry solid were defined as SBF.

\section{Flocculation Experiments}

To evaluate the flocculation effect of the prepared SBF, flocculation experiments were carried out. Starch suspension and oily wastewater were tested. Selected properties of the tested solutions were summarized in table1. The experimental procedures were as follows: different dosage of SBF was added to the beaker. The above flocculating system solution was diluted to $300.0 \mathrm{~mL}$. Afterwards, the flocculating system was stirred with a magnetic stirrer for $30 \mathrm{~s}$ at $400 \mathrm{rpm}$, slowly stirred at $100 \mathrm{rpm}$ for $5 \mathrm{~min}$ and then kept still for over $20 \mathrm{~min}$. The supernatant sample was collected for further analysis. The flocculating rate was defined and calculated using the following equation.

Table 1 Selected property for tested solutions

\begin{tabular}{llc}
\hline Solution & $\mathrm{pH}$ & $\mathrm{OD}$ \\
\hline Starch suspension & $6.0-7.0$ & 550 \\
Oily wastewater & $6.0-7.0$ & 268 \\
\hline
\end{tabular}

Flocculating rate $(\%)=(\mathrm{A}-\mathrm{B}) / \mathrm{A} \times 100$

Where A and B were OD of the blank control and the bulk solution, respectively.

\section{Analytical Methods}

Starch suspension absorbance, with 722 type spectrophotometer was measured under $550 \mathrm{~nm}$ wave lengths. The turbidity removal rate is the flocculating rate. COD was measured by fast digestion spectrophotometric method. The oil contents after flocculation were analyzed by ethyl acetate extraction test, and the oil contents of extracting agent were also analyzed by UV-VIS spectrophotometry. Each sample was read three times to get the average value.

\section{Results and Discussion}

In order to optimize the flocculation performance of wastewater using SBF which involves more than one mechanism, it is important to consider the influence factors which have effects on the flocculation mechanisms. In this section, the effect of some these factors, for example, the concentration of simulated wastewater $\left(\mathrm{C}_{0}\right)$, dosage of flocculant $(\mathrm{V})$, solution $\mathrm{pH}$ and settling time (t) on the flocculation efficiency of SBF was investigated.

\section{Starch Wastewater Treatment Using the Sludge Bioflocculant}

The $\mathrm{pH}$ of a flocculating mixture containing starch suspension and a certain amount of the SBF was adjusted with $0.01 \mathrm{~mol} / \mathrm{L} \mathrm{HCl}$ and $0.01 \mathrm{~mol} / \mathrm{L}$ sodium hydroxide solution before flocculating. Fig. 1 shows the flocculation efficiencies of the starch wastewater at different $\mathrm{pH}$, using $2.0 \mathrm{~mL}$ SBF in $300.0 \mathrm{~mL}$ of $4.0 \mathrm{~g} / \mathrm{L}$ starch solution. The turbidity of the supernatant was measured to calculate the flocculating rates after standing for $10 \mathrm{~min}$. According to Fig.1, with the increase of the initial $\mathrm{pH}$ the removal rate appears increasing at first and then not changes significantly after reaching the peak value. The flocculating rates were all over $90 \%$ in 
the range of $\mathrm{pH}$ 6.0-12.0, which was just the $\mathrm{pH}$ of the practical starch wastewater, so $\mathrm{pH}$ adjustment was not necessary any more in actual application.

The effect of SBF dosage on flocculation efficiency of starch wastewater was shown in Fig.2. Flocculating system $\mathrm{pH}$ was all adjusted to 6.0. Flocculating rate was more than $95.0 \%$ in a flocculant dosage range of $2.0-12.0 \mathrm{~mL}$. The maximum flocculating rate $99.5 \%$ was observed when the flocculant dosage was $8.0 \mathrm{~mL}$. When the flocculant dosage increases, the flocculating rate increased overall.

It can be seen from the above experimental results that SBF has a better flocculation effect on starch granules. The surface of the starch granules contains a large number of hydrophilic groups. After being in the water, starch granules have been swelling. Some hydroxyl groups on the surface of the particles ionization. It makes starch granules negatively charged, at the same time the surface forms the hydration layer. After adding the flocculating agent, positively charged flocculant quickly combined with starch granules, which can break the particles hydration layer. When particles lost stability, collision probability will be increased. Because the SBF attracted to each other at the same time, the larger particles of stable flocs can exist and settle down.

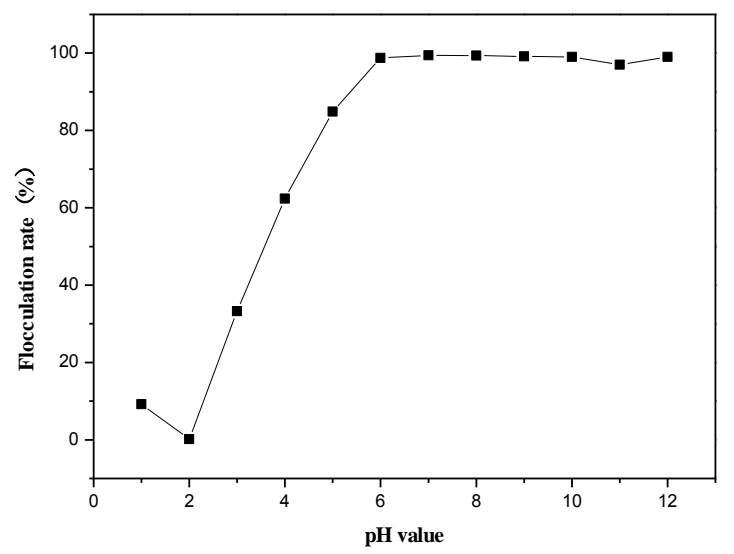

Fig. 1 The Relationship between PH Value of Starch Solution and Flocculation Activities

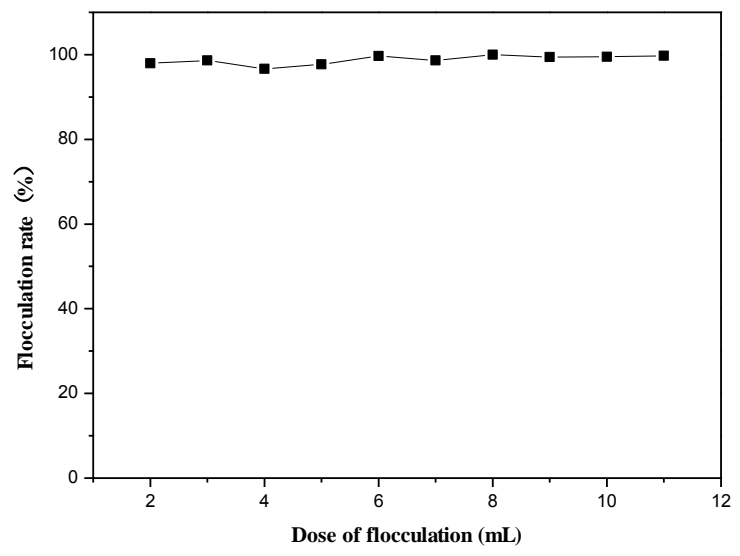

Fig. 2 The Relationship between Flocculant Dosage and The Rate of Starch Flocculation

\section{Oily Wastewater Treatment Using the Sludge Bioflocculant}

Chitosan, a natural cationic polyelectrolyte, and other similar coagulants were used in the treatment of an olive oil water suspension as a model for the processing wastewater. At optimum conditions of coagulation and flotation stages, the COD of the olive oil emulsion could be reduced 
by $95 \%$ [7]. In this study, we also found that SBF had specifically adsorption ability to tested oil wastewater. Oily wastewater $\mathrm{pH}$ is one of the main factors influencing the treatment effect of oily wastewater. The dosage of SBF was $4.0 \mathrm{~mL}$ for $300 \mathrm{~mL}$ oily wastewater. The oil-water mixture was stirred for $10 \mathrm{~min}$ by a magnetic stirrer at ambient temperature. After sedimentation for $30 \mathrm{~min}$ the middle part of the mixture was taken for measuring the absorbance under $268 \mathrm{~nm}$ wavelength with spectrophotometer of UV-VIS.

It can be seen from Fig.3, the flocculating rate increased first from $\mathrm{pH} 1.0-5.0$ and then decreased from 5.0-9.0. When the $\mathrm{pH}$ was 5.0 the flocculation efficiency presented peak, flocculation efficiency reached $92.0 \%$. Therefore, the best range of $\mathrm{pH}$ for oily wastewater is 4.0-6.0. However when the $\mathrm{pH}$ was 12.0 the flocculating rate was negative. The concentration of the oil in wastewater had been significantly decreased when the $\mathrm{pH}$ value reach 12.0. In neutral water, the absorbance of oil absorbency was 1.3, but in strong alkaline solution, that was 0.1 . It shows that the oil is broken. Experiments had shown that the clarity of oily wastewater before flocculating is low and oil had been dispersed evenly by stirring in the water. However, after the flocculating, the oil droplets gathered on the liquid surface which can be recycled. The spare liquor is clear and transparent. The oil removal efficiency can reach $91.0 \%$. Therefore the above experiment results show that the SBF has good oil and water separation capability. The SBF is a microbial flocculant which has many hydrophilic group and lipophilic group in the molecular structure [8]. So the interaction between lipophilic group and oil droplets can disrupt the hydration layer of oil and water. At the same time, it also can make a lot of oil droplets gathering to become thick oil layer that easily can be separated from water.

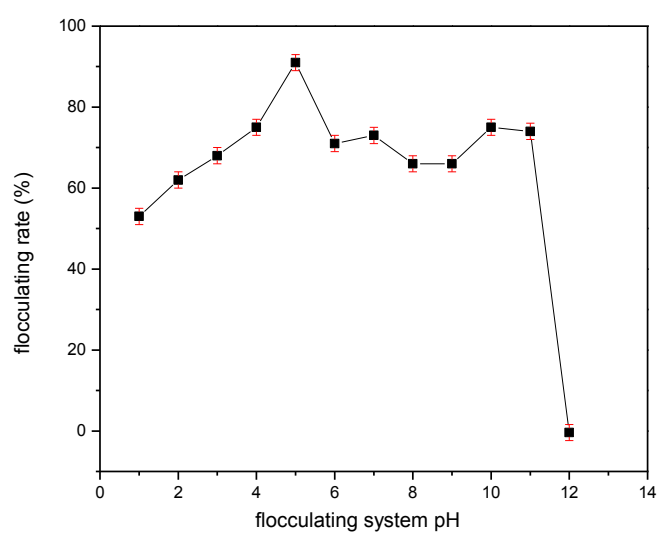

Fig. 3 The Relationship between PH Value of Oily Wastewater and Flocculation Activity

\section{Summary}

Excess biological sludge could be used as resources to prepare bioflocculants. Sludge bioflocculant had a good flocculation effect on starch granules. The flocculation efficiency reached $99.5 \%$. The SBF has a certain oil-water separation capability which can make the dispersed oil bead quickly gathering and stratification. The flocculation efficiency could reach $92.0 \%$. From the above study not only sludge could be recycled, a cheaper and readily available flocculant was attained from biological sludge, but also some kinds of wastewater could be disposed of with the sludge flocculant.

\section{Acknowledgement}

This work was supported by the Fundamental Research Funds for the Central Universities (NO.DUT17LK49) and the National Natural Science Funds of China (NO.51008046). 


\section{References}

[1] Tang, B., Zhang, Z. 2014. Essence of disposing the excess sludge and optimizing the operation of wastewater treatment: rheological behavior and microbial ecosystem. Chemosphere, 105, 1-13.

[2] Wei, Y., Van Houten, R.T., Borger, A.R., Eikelboom, D.H., Fan, Y. 2003. Minimization of excess sludge production for biological wastewater treatment. Water Research, 37(18), 4453-4467.

[3] Sun, J., Zhang, X., Miao, X., Zhou, J. 2012a. Preparation and characteristics of bioflocculants from excess biological sludge. Bioresour Technol, 126, 362-6.

[4] Gil-Lalaguna, N., Sánchez, J.L., Murillo, M.B., Ruiz, V., Gea, G. 2014. Air-steam gasification of char derived from sewage sludge pyrolysis. Comparison with the gasification of sewage sludge. Fuel, 129, 147-155.

[5] Pu, S.Y., Qin, L.L., Che, J.P., Zhang, B.R., Xu, M. 2014. Preparation and application of a novel bioflocculant by two strains of Rhizopus sp. using potato starch wastewater as nutrilite. Bioresour Technol, 162, 184-91.

[6] Sun, L., Wan, S., Yu, Z., Wang, Y., Wang, S. 2012b. Anaerobic biological treatment of high strength cassava starch wastewater in a new type up-flow multistage anaerobic reactor. Bioresour Technol, 104, 280-8.

[7] Meyssami, B., Kasaeian, A.B. 2005. Use of coagulants in treatment of olive oil wastewater model solutions by induced air flotation. Bioresour Technol, 96(3), 303-7.

[8] Zhang, X., Sun, J., Liu, X., Zhou, J. 2013. Production and flocculating performance of sludge bioflocculant from biological sludge. Bioresour Technol, 146, 51-6. 